\title{
Fizik Tabanlı Ses Sentezi Uygulamaları Üzerine Bir İnceleme
}

\author{
Elif Ekşi ${ }^{1}$, Fatma Nur Ak1², Rıfat Yazıc1² \\ ${ }^{1}$ İstanbul Ticaret Üniversitesi, Fen Bilimleri Enstitüsü, Bilgisayar Mühendisliği \\ Bölümü, İstanbul Türkiye \\ 2 İstanbul Ticaret Üniversitesi, Mühendislik Fakültesi, Bilgisayar Mühendisliği \\ Bölümü, İstanbul Türkiye
}

Geliş Tarihi: 19.08 .2020

*Sorumlu Yazar e mail: elifeksi95@gmail.com

Kabul Tarihi: 21.09 .2020

Atıf/Citation: Ekşi, E., Akı, F.N., Yazıcı R. "Fizik Tabanlı Ses Sentezi Uygulamaları Üzerine Bir İnceleme”, Haliç Üniversitesi Fen Bilimleri Dergisi 2020, 3/2: 289-308.

Derleme Makalelele/Review Articles

\section{Özet}

Bu çalışmada 1993-2020 yılları arasında yayınlanmış, fizik tabanlı ses simülasyonu konusunda yapılmış araştırmaları içeren yirmi dokuz adet makale taranmıştır. Özellikle birbirleri ile interaktif etkileşimde bulunan ve ses üreten cisimlerin simülasyonlarını içeren makaleler tercih edilmiştir. Makalelerde kullanılan fiziksel modeller ve çalışmaların kısa özeti bir tablo ile karşılaştırılmalı olarak burada verilmiştir. Bu çalışmalar incelendiğinde fizik tabanlı ses simülasyonu modellerinden Modal Sentezleme yönteminin on dört makalede ve Geometrik Model yönteminin yedi makalede ağırlıklı olarak kullanılan fiziksel model olduğu görülmüştür. Ayrıca araştırıcılar bu yöntemler ile birlikte Sonlu Elemanlar ve Sonlu Farklar metodunu da kullanmaktadır. Çalışmanın fiziksel tabanlı ses sentezi alanında yayın taraması yapan araştırmacılar için ilgili kaynaklara erişimde yardımcı olacağı ve ilgili literatüre katkısı olacağı düşünülmektedir.

Anahtar Kelimeler: Fizik tabanlı ses simülasyonu, modal sentezleme yöntemi, geometrik model.

\section{A Review on The Physics-Based Sound Synthesis Applications}

\begin{abstract}
In this study, twenty-nine articles which were published between 1993 and 2020 and which included the researches on the physics-based sound simulation were scanned.
\end{abstract}


The articles which included the simulations of the sound producing objects interacting with themselves were preferred especially. Here, the physical models used in the articles and a brief summary of the studies are given in a table comparatively. When these studies were examined, it was seen that the Modal Synthesis method, one of the physics-based sound simulation models, was preferred in 14 articles and the Geometric Model method in seven articles mainly. In addition, researchers also use the Finite Element and the Finite Difference methods together with these models. It is thought that the study will be helpful for accessing related source materials by the researchers who search for publications in the field of the physics-based sound synthesis and that it will contribute to the relevant literature.

Keywords: Physics-based sound simulation, modal model, geometric model.

\section{Giriş}

Bilgisayarların hesaplama güçlerinin artması ile cisimlerin interaktif görüntü ve ses simülasyonlarının üretimi günümüzde daha verimli hale gelmiştir. Simülasyonların fiziksel modele dönüştürülmesi, elde edilecek görüntü ve sesin daha gerçekçi olmasını sağlamaktadır. Ancak, grafik simülasyonlarına kıyasla, gerçekçi seslerin fiziksel modellere dayalı olarak simüle edilmesi son derece yüksek hesaplama maliyeti gerektirmesi nedeniyle hala araştırılmakta olan güncel bir konudur. Bu araştırmada ses simülasyonu yapılmış çalışmalar taranarak, hangi modellerin tercih edildiği özetlenmiştir (Tablo 1).

Fiziksel tabanlı ses sentezi yöntemleri, çarpışma gibi fiziksel etkileşimler esnasında oluşan sesi, cisimlerin malzeme cinsine ve geometrisine dayanan bazı faktörlere bağlı olarak ton ve tınıların değişikliğini otomatik olarak üretebilmektedir. Ancak, fiziksel tabanlı ses sentezi iki hesaplama gereksinimine sahiptir: 1) Fizik motoru. Bir fizik motoru, tam olarak çarpışan cisimlerin geometrisine dayanan ses üretimi için ses sistemini bilgilendirir. Örneğin Havok Engine (http://www.havok.com) gibi birçok yeni ticari fizik motoru bu ihtiyacı karşılayabilmektedir. 2) Daha büyük hesaplama kaynakları. Fiziksel tabanlı sesler, kaydedilen seslerden çok daha fazla hesaplama kaynağı kullanır. $\mathrm{Bu}$ 
nedenle, hiçbir zaman kaba kuvvet (brute-force) ile oluşturulmuş bir ses simülasyonu gerçek zamanlı performansa ulaşamamaktadır.

Tablo 1'de 1993-2020 yılları arasında yayınlanmış fiziksel modellere dayalı ses sentezi çalışmalarından seçilen 29 araştırma kısaca özetlenerek verilmiştir. İkinci bölümde bu yayınlarda kullanılmış olan en popüler yöntemlerin teorisi kısaca açıklanmıştır. 
Tablo 1. 1993-2020 yılları arasında taranmış makaleler

\begin{tabular}{|c|c|c|c|c|c|c|}
\hline Makalenin Adı & $\begin{array}{l}\text { Yayınlandığı } \\
\text { Yıl / Yazarlar }\end{array}$ & $\begin{array}{l}\text { Yayınlandığı yer / } \\
\text { Makale türü }\end{array}$ & $\begin{array}{c}\text { Modelle- } \\
\text { nen Fiziksel } \\
\text { Cisim veya } \\
\text { Olay }\end{array}$ & $\begin{array}{c}\text { Kullanılan } \\
\text { Yöntem veya } \\
\text { (fiziksel mo- } \\
\text { del) }\end{array}$ & Amacı & Sonucu \\
\hline $\begin{array}{l}\text { 1)Towards Hi- } \\
\text { gh-Quality Sound } \\
\text { Synthesis of the } \\
\text { Guitar and String } \\
\text { İnstruments (Gitar } \\
\text { ve yaylı Çalgıların } \\
\text { yüksek kaliteli ses } \\
\text { sentezine doğru) }\end{array}$ & $\begin{array}{c}\text { 1993/ } \\
\text { Karjalainen, M., } \\
\text { Välimäki, V., \& } \\
\text { Jánosy, Z. }\end{array}$ & $\begin{array}{c}\text { In Proceedings of } \\
\text { the International } \\
\text { Computer Music } \\
\text { Conference (pp. } \\
\text { 56-56). }\end{array}$ & $\begin{array}{c}\text { 1D } \\
\text { Gitar ve di- } \\
\text { ğer yaylı çal- } \\
\text { gllarda yüksek } \\
\text { kalitede ses } \\
\text { sentezleme }\end{array}$ & $\begin{array}{l}\text { Digital wave- } \\
\text { guide } \\
\text { (sayisal dalga } \\
\text { k1lavuzlu mo- } \\
\text { del) }\end{array}$ & $\begin{array}{c}\text { Gitarın ve diğer } \\
\text { yaylı çalgıların mo- } \\
\text { del tabanlı ses sente- } \\
\text { zini ses kalitesi açı- } \\
\text { sından daha gerçekçi } \\
\text { hale getirmek için } \\
\text { yeni ilkelerin su- } \\
\text { nulması } \\
\end{array}$ & $\begin{array}{c}\text { Akustik gitarı taklit eden } \\
\text { daha doğal sentetik seslerin } \\
\text { gerçek zamanlı olarak üreti- } \\
\text { lebilmesi. }\end{array}$ \\
\hline $\begin{array}{l}\text { 2)Physically Based } \\
\text { Sound Modelling } \\
\text { (Fiziksel Tabanl1 } \\
\text { Ses Modelleme) }\end{array}$ & $\begin{array}{c}\text { 1998/ } \\
\text { De Poli, G., \& } \\
\text { Rocchesso, D. }\end{array}$ & $\begin{array}{l}\text { Physically based } \\
\text { sound modelling. } \\
\text { Organised Sound, } \\
\text { 3(1), 61-76. }\end{array}$ & $\begin{array}{c}\text { 3D } \\
\text { Fiziksel Ta- } \\
\text { banlı Ses Mo- } \\
\text { delleme }\end{array}$ & $\begin{array}{l}\text { Finite Diffe- } \\
\text { rence method } \\
\text { (Sonlu farklar } \\
\text { metodu) }\end{array}$ & $\begin{array}{c}\text { Ses tanımı, yal- } \\
\text { nızca insan işitme- } \\
\text { sinin özelliklerine } \\
\text { değil, sesli nesne- } \\
\text { lerinin fiziğine da- } \\
\text { yandığı sürece, fizik } \\
\text { tabanlı grafik mo- } \\
\text { dellerle entegrasyo- } \\
\text { nun mümkün hale } \\
\text { gelmesi. }\end{array}$ & $\begin{array}{c}\text { Multimedya ortamlarında } \\
\text { görüntüler ve sesler ara- } \\
\text { sinda sıkı bir bağlantı kur- } \\
\text { maya çalışmak için yeni ça- } \\
\text { baların atılacağı umuduyla } \\
\text { hem sentez hem de işleme } \\
\text { aşamalarında ses ve görüntü } \\
\text { modelleri arasında meydana } \\
\text { gelen bazı ilişkilerin belir- } \\
\text { tilmesi }\end{array}$ \\
\hline $\begin{array}{l}\text { 3)Foleyautoma- } \\
\text { tic: Physically-ba- } \\
\text { sed Sound Effects } \\
\text { for Interactive Si- } \\
\text { mulation and Ani- } \\
\text { mation } \\
\text { (İnteraktif simülas- } \\
\text { yonlar ve animas- } \\
\text { yonlar için Fizik te- } \\
\text { melli ses efektleri) }\end{array}$ & $\begin{array}{c}\text { 2001/ } \\
\text { Van Den Doel, } \\
\text { K., Kry, P. G., \& } \\
\text { Pai, D. K. }\end{array}$ & $\begin{array}{l}\text { Proceeding /inte- } \\
\text { ractive techniques } \\
\text { (pp. 537-544)./ } \\
\text { Proceeding }\end{array}$ & $\begin{array}{l}\text { 3D Yuvarla- } \\
\text { nan Cisimle- } \\
\text { rin çıkardığı } \\
\text { sesler }\end{array}$ & $\begin{array}{c}\text { Modal Re- } \\
\text { zonans Model }\end{array}$ & $\begin{array}{l}\text { Metal bir tavada, et- } \\
\text { rafında zıplayabilen, } \\
\text { yuvarlanabilen ve } \\
\text { kayabilen bir çakıl } \\
\text { taşının ayrıntılı ha- } \\
\text { reketli simülasyonu- } \\
\text { nun gerçek-zamanda } \\
\text { oluşturulması }\end{array}$ & $\begin{array}{l}\text { Simülasyonda fiziğe daya- } \\
\text { nan ses sentezi algoritma- } \\
\text { ları kullanılarak, temaslar } \\
\text { ile dinamik bir simülasyon- } \\
\text { dan elde edilen fiziksel pa- } \\
\text { rametreler yönlendirilen } \\
\text { yüksek kaliteli gerçekçi te- } \\
\text { mas seslerini otomatik ola- } \\
\text { rak üretmek için bir yöntem } \\
\text { koleksiyonu açılanmış- } \\
\text { tır. Model parametreleri ta- } \\
\text { nımlandıktan sonra, sesler } \\
\text { otomatik olarak oluşturul- } \\
\text { maktadır. Bu durum etkile- } \\
\text { şimli simülasyon kullanıc1- } \\
\text { sina, nesnelere dokunurken, } \\
\text { onları kaydırırken veya yu- } \\
\text { varlarken gerçek hayattaki } \\
\text { işitsel geri bildirim deneyi- } \\
\text { mini sağlar. } \\
\end{array}$ \\
\hline $\begin{array}{l}\text { 4)Scanning Physi- } \\
\text { cal Interaction Be- } \\
\text { havior of 3D Ob- } \\
\text { jects } \\
\text { (3 Boyutlu cisim- } \\
\text { lerin fiziksel inte- } \\
\text { raksiyonların taran- } \\
\text { ması) }\end{array}$ & $\begin{array}{l}\text { 2001/ } \\
\text { Pai, D. K., Doel, } \\
\text { K. V. D., James, } \\
\text { D. L., Lang, J., } \\
\text { Lloyd, J. E., Ri- } \\
\text { chmond, J. L., } \\
\text { \& Yau, S. H. }\end{array}$ & $\begin{array}{l}\text { Proceeding / 28th } \\
\text { annual conference } \\
\text { on Computer } \\
\text { graphics and inte- } \\
\text { ractive techniques } \\
\text { (pp. } 87-96 \text { ). / Pro- } \\
\text { ceeding }\end{array}$ & $\begin{array}{l}\text { Gerçek cisim- } \\
\text { lerin taranmış } \\
\text { görüntüleri ile } \\
\text { 3D cisimlerin } \\
\text { üretilmesi }\end{array}$ & $\begin{array}{c}\text { Geometrik } \\
\text { Model } \\
\text { Modal Rezo- } \\
\text { nans Model }\end{array}$ & $\begin{array}{l}\text { Gerçek cisimlerin } \\
\text { yüzey dokuları ve } \\
\text { temas seslerinin ta- } \\
\text { ranması ile simü- } \\
\text { lasyon modellerinin } \\
\text { gerçek veriye ben- } \\
\text { zeştirilerek oluştu- } \\
\text { rulması }\end{array}$ & $\begin{array}{l}\text { Deformasyon (bir cismin } \\
\text { şekil değiştirmesi, şekil bo- } \\
\text { zukluğu, orijinal şeklinden } \\
\text { başkalaşmaya uğraması), } \\
\text { temas için yüzey dokusu ve } \\
\text { temas sesleri de dahil olmak } \\
\text { üzere çeşitli önemli etkile- } \\
\text { şim davranışlarının etkili } \\
\text { bir şekilde nasıl taranabile- } \\
\text { ceğini gösterilmiştir. }\end{array}$ \\
\hline
\end{tabular}




\begin{tabular}{|c|c|c|c|c|c|c|}
\hline Makalenin Adı & $\begin{array}{c}\text { Yayınlandığı } \\
\text { Yıl / Yazarlar }\end{array}$ & $\begin{array}{l}\text { Yayınlandığı yer / } \\
\text { Makale türü }\end{array}$ & $\begin{array}{c}\text { Modelle- } \\
\text { nen Fiziksel } \\
\text { Cisim veya } \\
\text { Olay } \\
\end{array}$ & \begin{tabular}{|c|} 
Kullanılan \\
Yöntem veya \\
(fiziksel mo- \\
del) \\
\end{tabular} & Amacı & Sonucu \\
\hline $\begin{array}{l}\text { 5) Synthesizing } \\
\text { Sounds from Phy- } \\
\text { sically Based Mo- } \\
\text { tion } \\
\text { (Fiziksel Tabanlı } \\
\text { Hareketten Sesleri } \\
\text { Sentezleme) }\end{array}$ & $\begin{array}{l}2001 \text { / O’Brien, } \\
\text { J. F., Cook, P. } \\
\text { R., \& Essl, G. }\end{array}$ & $\begin{array}{l}\text { In Proceedings of } \\
\text { the 28th annual } \\
\text { conference on } \\
\text { Computer grap- } \\
\text { hics and intera- } \\
\text { ctive techniques } \\
\text { (pp. 529-536). / } \\
\text { Proceeding }\end{array}$ & $\begin{array}{l}\text { 3D katı cisim- } \\
\text { lerin bir yü- } \\
\text { zeye çarpa- } \\
\text { rak sıçrarken } \\
\text { ve yuvarlanır- } \\
\text { ken çıkardığı } \\
\text { sesler }\end{array}$ & $\begin{array}{l}\text { Finite Ele- } \\
\text { ment Method } \\
\text { (Sonlu Ele- } \\
\text { manlar Yön- } \\
\text { temi) } \\
\text { Sesin yayllımı } \\
\text { için: Akustik } \\
\text { Dalga Modeli }\end{array}$ & $\begin{array}{l}\text { Katı nesnelerin ha- } \\
\text { reketiyle üretilen ve } \\
\text { ortama yayılan ses- } \\
\text { lerin bilgisayar si- } \\
\text { mülasyonu ile mo- } \\
\text { dellenmesi }\end{array}$ & $\begin{array}{c}\text { Başarılı bir şekilde fizik ta- } \\
\text { banlı realistik ses üretil- } \\
\text { miştir. }\end{array}$ \\
\hline $\begin{array}{l}\text { 6)Physically-based } \\
\text { real-time modeling } \\
\text { of contact sounds } \\
\text { (Temas seslerinin } \\
\text { gerçek zamanda fi- } \\
\text { zik tabanlı model- } \\
\text { lenmesi) }\end{array}$ & $\begin{array}{l}\text { 2002/ } \\
\text { Rath, M., Roc- } \\
\text { chesso, D., \& } \\
\text { Avanzini, F. }\end{array}$ & $\begin{array}{l}\text { Physically ba- } \\
\text { sed real-time mo- } \\
\text { deling of con- } \\
\text { tact sounds. In } \\
\text { Proc. Int. Compu- } \\
\text { ter Music Conf.). / } \\
\text { Proceeding }\end{array}$ & $\begin{array}{c}\text { 3D } \\
\text { Seslerin ger- } \\
\text { çek zamanlı } \\
\text { modellen- } \\
\text { mesi }\end{array}$ & $\begin{array}{c}\text { Modal Rezo- } \\
\text { nans Model }\end{array}$ & $\begin{array}{l}\text { Düşük maliyetli } \\
\text { platformlarda gerçek } \\
\text { zamanlı olarak çalı- } \\
\text { şan modellerin sez- } \\
\text { gisel pratik kullanı- } \\
\text { labilirliği. }\end{array}$ & $\begin{array}{l}\text { Modelden üretilen sesin ka- } \\
\text { litesi hem resmi olmayan } \\
\text { değerlendirmeler hem de } \\
\text { genel olarak resmi dinleme } \\
\text { testleri ile değerlendirilip, } \\
\text { etki sesleri gerçekçi olarak } \\
\text { algılanmaktadır. Etki yeri } \\
\text { üzerindeki kontrol inandı- } \\
\text { rıcı sonuçlar vermektedir. }\end{array}$ \\
\hline $\begin{array}{l}\text { 7)Sound Produc- } \\
\text { tion and Modeling } \\
\text { (Ses Üretme ve } \\
\text { Modelleme) }\end{array}$ & $\begin{array}{c}\text { 2002/ } \\
\text { Cook, P. R. }\end{array}$ & $\begin{array}{l}\text { Sound produc- } \\
\text { tion and modeling. } \\
\text { IEEE Computer } \\
\text { Graphics and app- } \\
\text { lications, 22(4), } \\
\text { 23-27. }\end{array}$ & $\begin{array}{c}1 \mathrm{D} \\
\text { Bir boyutlu ci- } \\
\text { simlerin (tel, } \\
\text { ip vb.) ürettiği } \\
\text { sesin model- } \\
\text { lenmesi }\end{array}$ & $\begin{array}{l}\text { Modal Synt- } \\
\text { hesis Model } \\
\text { (Modal Sen- } \\
\text { tezleme) }\end{array}$ & $\begin{array}{l}\text { Sesi fiziksel bir olgu } \\
\text { olarak tanımlama, } \\
\text { sesin insanlar tara- } \\
\text { findan algılanmasını } \\
\text { sağlama. }\end{array}$ & $\begin{array}{l}\text { 3B ses, sanal ve artırılmış } \\
\text { gerçeklikte ses üretilmiştir. }\end{array}$ \\
\hline $\begin{array}{l}\text { 8)Physically Infor- } \\
\text { med Signal Proces- } \\
\text { sing Methods for } \\
\text { Piano Sound Synt- } \\
\text { hesis: A Research } \\
\text { Overview } \\
\text { (Piyano Ses Sen- } \\
\text { tezi için Fiziksel } \\
\text { Bilgili Sinyal İş- } \\
\text { leme Yöntemleri: } \\
\text { Araştırmaya Genel } \\
\text { Bakış) }\end{array}$ & $\begin{array}{l}\text { 2003/ } \\
\text { Bank, B., Avan- } \\
\text { zini, F., Borin, } \\
\text { G., De Poli, G., } \\
\text { Fontana, F., \& } \\
\text { Rocchesso, D. }\end{array}$ & $\begin{array}{l}\text { EURASIP Jour- } \\
\text { nal on Advances } \\
\text { in Signal Proces- } \\
\text { sing, 2003(10), } \\
464536 .\end{array}$ & $\begin{array}{c}1 \mathrm{D} \\
\text { Ses kartı mo- } \\
\text { deli için filtre } \\
\text { tabanlı bir } \\
\text { yaklaşımın su- } \\
\text { nulması }\end{array}$ & $\begin{array}{c}\text { Akustik Dalga } \\
\text { Modeli }\end{array}$ & $\begin{array}{l}\text { Piyanonun fizik ta- } \\
\text { banlı sentezindeki } \\
\text { son gelişmeleri göz- } \\
\text { den geçirmek }\end{array}$ & $\begin{array}{l}\text { Bu makale, piyano için fi- } \\
\text { ziksel bir model geliştirme- } \\
\text { nin ana aşamalarını gözden } \\
\text { geçirmiş, hesaplamalı yön- } \\
\text { leri ele almış ve sadece pi- } \\
\text { yano sentezi ile ilgili değil, } \\
\text { aynı zamanda geniş bir ses } \\
\text { sınıfı nesne modellerinde } \\
\text { ortaya çıkan sorunları tar- } \\
\text { tışmıştır. }\end{array}$ \\
\hline $\begin{array}{l}\text { 9)Physically-Based } \\
\text { Models For Liquiid } \\
\text { Sounds } \\
\text { (Siv1 Cisimlerin } \\
\text { Ürettiği Sesler İçin } \\
\text { Fiziksel Tabanlı } \\
\text { Modeller) }\end{array}$ & $\begin{array}{c}\text { 2005/ } \\
\text { Doel, K. V. D. }\end{array}$ & $\begin{array}{l}\text { Physically based } \\
\text { models for liquid } \\
\text { sounds. ACM } \\
\text { Transactions on } \\
\text { Applied Percep- } \\
\text { tion (TAP), 2(4), } \\
534-546 .\end{array}$ & $\begin{array}{c}\text { 3D } \\
\text { Fiziksel ta- } \\
\text { banlı sıv1 ci- } \\
\text { sim için ses } \\
\text { sentezi }\end{array}$ & $\begin{array}{l}\text { Modal Sentez- } \\
\text { leme }\end{array}$ & $\begin{array}{c}\text { Su tarafindan ya- } \\
\text { p1lan seslerin ger- } \\
\text { çek zamanlı sentezi } \\
\text { için fiziksel tabanlı } \\
\text { bir modelin oluştu- } \\
\text { rulması. }\end{array}$ & $\begin{array}{l}\text { Gerçek zamanlı parametrik } \\
\text { kontrol altında çok çeşitli } \\
\text { sivı ses efektleri oluşturmak } \\
\text { için bir baloncuk popülas- } \\
\text { yonunu harekete geçirmek } \\
\text { için istatistiksel modeller } \\
\text { kullanan gerçek zamanlı bir } \\
\text { sivı ses sentezleyici oluştu- } \\
\text { rulması. }\end{array}$ \\
\hline
\end{tabular}




\begin{tabular}{|c|c|c|c|c|c|c|}
\hline Makalenin Adı & $\begin{array}{l}\text { Yayınlandığı } \\
\text { Yıl / Yazarlar }\end{array}$ & $\begin{array}{l}\text { Yayınlandığı yer / } \\
\text { Makale türü }\end{array}$ & $\begin{array}{c}\text { Modelle- } \\
\text { nen Fiziksel } \\
\text { Cisim veya } \\
\text { Olay } \\
\end{array}$ & \begin{tabular}{|c|} 
Kullanılan \\
Yöntem veya \\
(fiziksel mo- \\
del) \\
\end{tabular} & Amacı & Sonucu \\
\hline $\begin{array}{l}\text { 10)Physically-ba- } \\
\text { sed Sound Synthe- } \\
\text { sis on GPUs } \\
\text { Grafik İşlemcilerde } \\
\text { (GPU) Fizik Ta- } \\
\text { banlı Ses Sentezi }\end{array}$ & $\begin{array}{c}\text { 2005/ } \\
\text { Zhang, Q., Ye, } \\
\text { L., \& Pan, Z. }\end{array}$ & $\begin{array}{l}\text { Physically-based } \\
\text { sound synthesis on } \\
\text { GPUs. In Interna- } \\
\text { tional Conference } \\
\text { on Entertainment } \\
\text { Computing (pp. } \\
\text { 328-333). Sprin- } \\
\text { ger, Berlin, Hei- } \\
\text { delberg. }\end{array}$ & $\begin{array}{c}\text { 2D } \\
\text { Modal sentez } \\
\text { için GPU ta- } \\
\text { banlı bir uy- } \\
\text { gulamanın } \\
\text { önerilmesi. }\end{array}$ & $\begin{array}{l}\text { (Modal Sen- } \\
\text { tezleme) }\end{array}$ & $\begin{array}{l}\text { GPU'lar üzerinde } \\
\text { modsal sentezin uy- } \\
\text { gulanması, gerçek } \\
\text { zamanlı olarak sen- } \\
\text { tezlenebilecek mod } \\
\text { sayısının önemli öl- } \\
\text { çüde geliştirilmesi. }\end{array}$ & $\begin{array}{l}\text { GPU ile sistem belleği ara- } \\
\text { sindaki veri aktarım bant } \\
\text { genişliğinin sürekli olarak } \\
\text { artmasından dolayı, GPU } \\
\text { tabanlı uygulamanı CPU } \\
\text { tabanlıya göre daha fazla } \\
\text { performans artışı vermesi } \\
\text { beklenmektedir. }\end{array}$ \\
\hline $\begin{array}{l}\text { 11)Interactive } \\
\text { Sound Synthesis } \\
\text { for Large Scale En- } \\
\text { vironments } \\
\text { (Büyük Ölçekli Or- } \\
\text { tamlar için Etkile- } \\
\text { şimli Ses Sentezi) }\end{array}$ & $\begin{array}{c}\text { 2006/ } \\
\text { Raghuvanshi, } \\
\text { N., \& Lin, M. C. }\end{array}$ & \begin{tabular}{|l|} 
Interactive sound \\
synthesis for large \\
scale environ- \\
ments. In Procee- \\
dings of the 2006 \\
symposium on In- \\
teractive 3D grap- \\
hics and games \\
(pp. 101-108).
\end{tabular} & \begin{tabular}{|c|} 
3D \\
Katı cisimle- \\
rin bir yüzeye \\
çarparak sıç- \\
rarken ve yu- \\
varlanırken çı- \\
kardığı sesler
\end{tabular} & $\begin{array}{l}\text { Modal Sentez- } \\
\text { leme } \\
\text { Kütle -Yay } \\
\text { Sistemleri } \\
\text { (Spring-mass } \\
\text { Systems) }\end{array}$ & $\begin{array}{l}\text { Katı-cisim dinamik } \\
\text { simülasyonlarından } \\
\text { gerçekçi fiziksel ta- } \\
\text { banlı sesler üretmek }\end{array}$ & $\begin{array}{l}\text { Yüzlerce etkileşimli nesne- } \\
\text { den oluşan büyük ölçekli } \\
\text { bir olayı gecçek zamanlı } \\
\text { olarak oluşturmak için alg1- } \\
\text { lanan ses kalitesinde çok az } \\
\text { kayıpla çeşitli hızlandırma } \\
\text { tekniklerine sahip fiziksel } \\
\text { tabanlı bir ses sentezi algo- } \\
\text { ritmasının oluşturulması. }\end{array}$ \\
\hline $\begin{array}{l}\text { 12)Precomputed } \\
\text { Acoustic Transfer: } \\
\text { Output-sensitive, } \\
\text { accurate sound ge- } \\
\text { neration for geo- } \\
\text { metrically complex } \\
\text { vibration sources } \\
\text { (Önceden Hesap- } \\
\text { lanmış Akustik Ak- } \\
\text { tarım: Geometrik } \\
\text { olarak karmaşı tit- } \\
\text { reşim kaynakları } \\
\text { için çıkışa duyarlı, } \\
\text { doğru ses üretimi) }\end{array}$ & $\begin{array}{l}\text { 2006/ } \\
\text { Barbic, D. L. J. } \\
\text { J., \& Pai, D. K. }\end{array}$ & \begin{tabular}{|l|} 
ACM Transac- \\
tions on Grap- \\
hics (TOG), 25(3), \\
987-995.
\end{tabular} & $\begin{array}{c}\text { 3D } \\
\text { Geometrik } \\
\text { olarak karma- } \\
\text { şık titreşimli } \\
\text { nesnelerden } \\
\text { ses radyas- } \\
\text { yonu sentezle- } \\
\text { mek için hızlı } \\
\text { bir yöntemin } \\
\text { tanımlanması }\end{array}$ & $\begin{array}{c}\text { Akustik Dalga } \\
\text { Modeli }\end{array}$ & $\begin{array}{l}\text { Fiziksel tabanlı ani- } \\
\text { masyonda gerçek } \\
\text { zamanlı ses sente- } \\
\text { zini mümkün kılan } \\
\text { eşdeğer kaynak yak- } \\
\text { laşımları oluşturmak } \\
\text { için bir algoritmanın } \\
\text { sunulması }\end{array}$ & $\begin{array}{l}\text { Katı cisimlerden gelen ger- } \\
\text { çekçi ses radyasyonunun } \\
\text { gerçek zamanlı sentezi için } \\
\text { yeni bir algoritma oluştu- } \\
\text { rulması }\end{array}$ \\
\hline $\begin{array}{l}\text { 13)Physically Ba- } \\
\text { sed Sound Synthe- } \\
\text { sis for Large-Scale } \\
\text { Virtual Environ- } \\
\text { ments } \\
\text { (Büyük Ölçekli Sa- } \\
\text { nal Ortamlar için } \\
\text { Fiziksel Tabanlı } \\
\text { Ses Sentezi) }\end{array}$ & $\begin{array}{c}2007 / \\
\text { Raghuvanshi, } \\
\text { N., \& Lin, M. C. }\end{array}$ & $\begin{array}{l}\text { IEEE Computer } \\
\text { Graphics and App- } \\
\text { lications, 27(1), } \\
\text { 14-18. }\end{array}$ & \begin{tabular}{|c|} 
3D \\
Büyük ölçekli \\
sanal ortam- \\
lar için ger- \\
çekçi, fizik- \\
sel tabanlı ses \\
sentezini sağ- \\
lama
\end{tabular} & \begin{tabular}{|l} 
Modal Sentez- \\
leme \\
Kütle -Yay \\
Modeli \\
(Spring-mass \\
model)
\end{tabular} & $\begin{array}{l}\text { Ses simülasyonunu } \\
\text { hızlandırmak için } \\
\text { çeşitli tekniklerin ta- } \\
\text { nımlanması ve bü- } \\
\text { yük ölçekli sanal or- } \\
\text { tamlar için gerçekçi, } \\
\text { fizik tabanlı ses sen- } \\
\text { tezini sağlamak }\end{array}$ & $\begin{array}{l}\text { Günümüzün sanal ortamla- } \\
\text { rının çok sayıda sesli nes- } \\
\text { neler içeren sahneler için } \\
\text { fizik tabanlı sesleri destek- } \\
\text { leyebileceğini açıkça gös- } \\
\text { termektedir }\end{array}$ \\
\hline $\begin{array}{l}\text { 14) Block-Based } \\
\text { Physical Modeling } \\
\text { for Digital Sound } \\
\text { Synthesis } \\
\text { (Dijital Ses Sen- } \\
\text { tezi için Blok Ta- } \\
\text { banll Fiziksel Mo- } \\
\text { delleme) }\end{array}$ & $\begin{array}{l}\text { 2007/ } \\
\text { Rabenstein, R., } \\
\text { Petrausch, S., } \\
\text { Sarti, A., De } \\
\text { Sanctis, G., Er- } \\
\text { kut, C., \& Kar- } \\
\text { jalainen, M. }\end{array}$ & $\begin{array}{l}\text { IEEE Signal Pro- } \\
\text { cessing Magazine, } \\
24(2), 42-54\end{array}$ & $\begin{array}{c}\text { 2D } \\
\text { Blok tabanlı } \\
\text { fiziksel mo- } \\
\text { delleme }\end{array}$ & $\begin{array}{l}\text { Sonlu farklar } \\
\text { metodu }\end{array}$ & $\begin{array}{l}\text { Kullanıcıyı blok } \\
\text { uyumluluğu sorun- } \\
\text { ları ile zorlamadan } \\
\text { karmaşık ses sentezi } \\
\text { sistemlerinin oluştu- } \\
\text { rulmasına izin veren } \\
\text { yazılım ortamlarının } \\
\text { sunulması }\end{array}$ & $\begin{array}{l}\text { Gerçek zamanlı operas- } \\
\text { yon, etkileşimli insan kont- } \\
\text { rolü ve düşük gecikmeli pa- } \\
\text { rametre varyasyonları için } \\
\text { otomatik olarak oluşturu- } \\
\text { lan sentez algoritmalarının } \\
\text { oluşturulması }\end{array}$ \\
\hline
\end{tabular}




\begin{tabular}{|c|c|c|c|c|c|c|}
\hline Makalenin Adı & $\begin{array}{l}\text { Yayınlandığı } \\
\text { Yıl / Yazarlar }\end{array}$ & $\begin{array}{l}\text { Yayınlandığı yer / } \\
\text { Makale türü }\end{array}$ & $\begin{array}{l}\text { Modellenen } \\
\text { Fiziksel Ci- } \\
\text { sim ve Olay }\end{array}$ & $\begin{array}{c}\text { Kullanılan } \\
\text { Yöntem veya } \\
\text { (fiziksel mo- } \\
\text { del) }\end{array}$ & Amacı & Sonucu \\
\hline $\begin{array}{l}\text { 15)Synthesis of } \\
\text { Hand Clapping } \\
\text { Sounds } \\
\text { (El Çırpma Sesleri- } \\
\text { nin Sentezi) }\end{array}$ & $\begin{array}{l}\text { 2007/ } \\
\text { Peltola, L., Er- } \\
\text { kut, C., Cook, } \\
\text { P. R., \& Vali- } \\
\text { maki, V. }\end{array}$ & $\begin{array}{l}\text { IEEE Transactions } \\
\text { on Audio, Spe- } \\
\text { ech, and Language } \\
\text { Processing, 15(3), } \\
1021-1029 .\end{array}$ & $\begin{array}{c}3 \mathrm{D} \\
\text { El çırpma ses- } \\
\text { lerinin sen- } \\
\text { tezi }\end{array}$ & $\begin{array}{c}\text { Physically In- } \\
\text { formed Stoc- } \\
\text { hastic Event } \\
\text { Modeling } \\
\text { (PhISEM) } \\
\text { Stokastik } \\
\text { Olay Model- } \\
\text { leme }\end{array}$ & $\begin{array}{c}\text { El çırpma seslerinin } \\
\text { üretimi }\end{array}$ & $\begin{array}{l}\text { El çırpma seslerini sentez- } \\
\text { lemek için iki fizik tabanlı } \\
\text { analiz, sentez ve kontrol } \\
\text { sisteminin sunulması. }\end{array}$ \\
\hline $\begin{array}{l}\text { 16)Discrete Elas- } \\
\text { tic Rods } \\
\text { (Ayrık Elastik Çu- } \\
\text { buklar) }\end{array}$ & $\begin{array}{l}\text { 2008/ } \\
\text { Bergou, M., } \\
\text { Wardetzky, M., } \\
\text { Robinson, S., } \\
\text { Audoly, B., \& } \\
\text { Grinspun, E. }\end{array}$ & $\begin{array}{l}\text { In ACM SIGG- } \\
\text { RAPH 2008 pa- } \\
\text { pers (pp. 1-12). }\end{array}$ & $\begin{array}{l}\quad \text { 3D } \\
\text { Hem verimli } \\
\text { hem de iyi } \\
\text { enerji dav- } \\
\text { ranışına sa- } \\
\text { hip yöntemleri } \\
\text { uygulamak } \\
\text { için alternatif } \\
\text { yöntemlerin } \\
\text { araştırılması }\end{array}$ & $\begin{array}{c}\text { Geometrik } \\
\text { Model }\end{array}$ & $\begin{array}{l}\text { Çubukları sert ci- } \\
\text { simlere bağlamak } \\
\text { ve aynı zamanda çu- } \\
\text { bukların uzamasını } \\
\text { sağlamak için çeşitli } \\
\text { projeksiyon yönte- } \\
\text { minin açıklanması. }\end{array}$ & $\begin{array}{l}\text { Elastik çubukların simülas- } \\
\text { yonu için yüksek dereceli } \\
\text { yöntemler sağlanmaktadır. }\end{array}$ \\
\hline $\begin{array}{l}\text { 17)Harmonic } \\
\text { Shells: A Practical } \\
\text { Nonlinear Sound } \\
\text { Model for Near-Ri- } \\
\text { gid Thin Shells } \\
\text { (Harmonik Kabuk- } \\
\text { lar: Katı İnce Ka- } \\
\text { buklar için Pratik } \\
\text { Doğrusal Olmayan } \\
\text { Ses Modeli) }\end{array}$ & $\begin{array}{c}\text { 2009/ } \\
\text { Chadwick, J. N., } \\
\text { An, S. S., \& Ja- } \\
\text { mes, D. L. }\end{array}$ & $\begin{array}{l}\text { ACM Trans. } \\
\text { Graph., 28(5), } \\
119 .\end{array}$ & $\begin{array}{c}\text { 3D } \\
\text { Ince kabuk- } \\
\text { lar için olası } \\
\text { çarpma sesleri } \\
\text { üretmek }\end{array}$ & $\begin{array}{l}\text { Modal Sentez- } \\
\text { leme }\end{array}$ & $\begin{array}{l}\text { İnce kabukların tit- } \\
\text { reşimleri nedeniyle } \\
\text { olası gerçek seslerin } \\
\text { üretilmesi }\end{array}$ & $\begin{array}{l}\text { Doğrusal modal ses model- } \\
\text { leriyle karşılaştırıldığında, } \\
\text { nesneler daha özgün "çar- } \\
\text { pışma" ve "gürleme" ses- } \\
\text { leri üretir. }\end{array}$ \\
\hline $\begin{array}{l}\text { 18)Harmonic Flu- } \\
\text { ids } \\
\text { (Harmonik Sivilar) }\end{array}$ & $\begin{array}{l}\text { 2009/ } \\
\text { Zheng, C., \& Ja- } \\
\text { mes, D. L. }\end{array}$ & $\begin{array}{l}\text { Harmonic flu- } \\
\text { ids. ACM Tran- } \\
\text { sactions on Grap- } \\
\text { hics (TOG), 28(3), } \\
1-12 .\end{array}$ & $\begin{array}{c}\text { 3D } \\
\text { Harmonik } \\
\text { Sıvı olguları } \\
\text { için fizik ta- } \\
\text { banlı ses oluş- } \\
\text { turma }\end{array}$ & $\begin{array}{c}\text { Geometrik } \\
\text { Model }\end{array}$ & $\begin{array}{l}\text { 3D sıvı animasyon- } \\
\text { larından senkronize } \\
\text { harmonik kabar- } \\
\text { cık tabanlı seslerin } \\
\text { otomatik yöntem- } \\
\text { sel sentezi çcin pra- } \\
\text { tik bir metodun öne- } \\
\text { rilmesi. }\end{array}$ & $\begin{array}{l}\text { Dört farklı su sesi için so- } \\
\text { nuçlar: düşen su damlaları, } \\
\text { bir musluktan dökülen su, } \\
\text { düşen sert bir nesnenin sıç- } \\
\text { rattığı su. }\end{array}$ \\
\hline
\end{tabular}




\begin{tabular}{|c|c|c|c|c|c|c|}
\hline Makalenin Adı & $\begin{array}{l}\text { Yayınlandığı } \\
\text { Yıl / Yazarlar }\end{array}$ & $\begin{array}{l}\text { Yayınlandığı yer / } \\
\text { Makale türü }\end{array}$ & $\begin{array}{l}\text { Modellenen } \\
\text { Fiziksel Ci- } \\
\text { sim ve Olay }\end{array}$ & $\begin{array}{c}\text { Kullanılan } \\
\text { Yöntem veya } \\
\text { (fiziksel mo- } \\
\text { del) }\end{array}$ & Amacı & Sonucu \\
\hline $\begin{array}{l}\text { 19)Animating Fire } \\
\text { with Sound } \\
\text { (Ses ile yangın ani- } \\
\text { masyonu) }\end{array}$ & $\begin{array}{c}\text { 2011/ } \\
\text { Chadwick, J. N., } \\
\text { \& James, D. L. }\end{array}$ & $\begin{array}{l}\text { ACM Transacti- } \\
\text { ons on Graphics } \\
\text { (TOG), 30(4), 1-8. }\end{array}$ & $\begin{array}{c}3 \mathrm{D} \\
\text { Fizik tabanlı } \\
\text { ateş simü- } \\
\text { lasyonları ile } \\
\text { senkronize } \\
\text { edilen olası } \\
\text { seslerin sen- } \\
\text { tezlenmesi } \\
\text { için bir yön- } \\
\text { temin sunul- } \\
\text { ması. }\end{array}$ & $\begin{array}{c}\text { Geometrik } \\
\text { Model }\end{array}$ & $\begin{array}{l}\text { Fizik tabanlı ateş si- } \\
\text { mülasyonları ile } \\
\text { senkronize edilmiş } \\
\text { olası seslerin sentez- } \\
\text { lenmesi }\end{array}$ & $\begin{array}{l}\text { Düşük hızlarda zaman ka- } \\
\text { demeli simülasyonlardan } \\
\text { sesler üretir, daha sonra } \\
\text { spektral bant genişliği ge- } \\
\text { nişletme veya doku sentezi } \\
\text { tekniklerini kullanarak bir } \\
\text { işlem sonrası olarak yüksek } \\
\text { frekanslı içeriğin sunulması. }\end{array}$ \\
\hline $\begin{array}{l}\text { 20)Precomputed } \\
\text { Acceleration Noise } \\
\text { for Improved Ri- } \\
\text { gid-Body Sound } \\
\text { (Katı Cisim Sesi } \\
\text { için Önceden He- } \\
\text { saplanmış Hız- } \\
\text { lanma Gürültüsü) }\end{array}$ & $\begin{array}{c}\text { 2012/ } \\
\text { Chadwick, J. N., } \\
\text { Zheng, C., \& Ja- } \\
\text { mes, D. L. }\end{array}$ & $\begin{array}{l}\text { ACM Transacti- } \\
\text { ons on Graphics } \\
\text { (TOG), 31(4), 1-9. }\end{array}$ & $\begin{array}{c}3 \mathrm{D} \\
\text { Bir nesne çar- } \\
\text { pışmalar veya } \\
\text { diğer temas } \\
\text { olayları ne- } \\
\text { deniyle bir } \\
\text { katı cisim hız- } \\
\text { lanma yaşadı- } \\
\text { ğında bu üre- } \\
\text { tilen hızlanma } \\
\text { sesini sentez- } \\
\text { lemek } \\
\end{array}$ & $\begin{array}{c}\text { Geometrik } \\
\text { Model }\end{array}$ & $\begin{array}{l}\text { Çarpışan ve diğer } \\
\text { temas olayları so- } \\
\text { nucunda çıkan sesi } \\
\text { sentezleme }\end{array}$ & $\begin{array}{l}\text { Katı cisim hızlanma sesini } \\
\text { sentezlemek için bir mode- } \\
\text { lin sunulması. Hızlanma se- } \\
\text { sinin eklenmesi, çeşitli katı } \\
\text { cisim örnekleri için ses kali- } \\
\text { tesini önemli ölçüde artırır. }\end{array}$ \\
\hline $\begin{array}{l}\text { 21)Motion-driven } \\
\text { Concatenative Sy- } \\
\text { nthesis of Cloth } \\
\text { Sounds } \\
\text { (Kumaş Seslerinin } \\
\text { Hareket odaklı bir- } \\
\text { leștirici sentezi) }\end{array}$ & $\begin{array}{c}\quad \text { 2012/ } \\
\text { An, S. S., Ja- } \\
\text { mes, D. L., \& } \\
\text { Marschner, S. }\end{array}$ & $\begin{array}{l}\text { ACM Transac- } \\
\text { tions on Grap- } \\
\text { hics (TOG), 31(4), } \\
1-10 .\end{array}$ & $\begin{array}{c}3 \mathrm{D} \\
\text { Kumaş ani- } \\
\text { masyonları } \\
\text { için olası ses } \\
\text { sentezi }\end{array}$ & $\begin{array}{c}\text { Geometrik } \\
\text { Model }\end{array}$ & $\begin{array}{c}\text { Grafik hızlarında ça- } \\
\text { lışan fizik tabanlı } \\
\text { kumaş animasyon- } \\
\text { ları için olası sesleri } \\
\text { otomatik olarak sen- } \\
\text { tezlemek için pratik } \\
\text { bir veri odaklı yön- } \\
\text { temin sunulması. }\end{array}$ & $\begin{array}{l}\text { 3D kumaş animasyonla- } \\
\text { rında seslerin otomatik bir- } \\
\text { leştirme sentezi için veriye } \\
\text { dayalı bir yöntemin sunul- } \\
\text { ması. İki özel ses üreten ol- } \\
\text { guda, sürtünmeye ve bu- } \\
\text { ruşmaya odaklanılır ve } \\
\text { bunların çeşitli animasyonlu } \\
\text { kumaş senaryoları için ye- } \\
\text { terli olduğu gösterildi. }\end{array}$ \\
\hline $\begin{array}{l}\text { 22)Large Scale } \\
\text { Physical Modeling } \\
\text { Sound Synthesis } \\
\text { (Büyük Ölçekli Fi- } \\
\text { ziksel Modelleme } \\
\text { Ses Sentezi) }\end{array}$ & $\begin{array}{c}\text { 2013/ } \\
\text { Bilbao, S., Ha- } \\
\text { milton, B., To- } \\
\text { rin, A., Webb, } \\
\text { C., Graham, P., } \\
\text { Gray, A., ... \& } \\
\text { Perry, J. }\end{array}$ & $\begin{array}{l}\text { In Proceedings } \\
\text { of the Stockholm } \\
\text { music acous- } \\
\text { tic conference } \\
\text { (SMAC2013), } \\
\text { Stockholm (pp. } \\
\text { 593-600). }\end{array}$ & $\begin{array}{c}3 \mathrm{D} \\
\text { Fiziksel mo- } \\
\text { dellere dayalı } \\
\text { ses sentezi }\end{array}$ & $\begin{array}{c}\text { Finite Diffe- } \\
\text { rence Time } \\
\text { Domain Met- } \\
\text { hod }\end{array}$ & $\begin{array}{l}\text { FDTD ve Sonlu ha- } \\
\text { cim zaman alanı } \\
\text { yöntemleri gibi bü- } \\
\text { yük ölçekli zaman } \\
\text { adım yöntemleri, } \\
\text { ince Plaka ve ka- } \\
\text { buk titreşimine da- } \\
\text { yanan vurmalı çal- } \\
\text { gılar ve ayrıca 3D } \\
\text { akustik alanlara gö- } \\
\text { mülmeleri de dahil } \\
\text { olmak üzere müzik } \\
\text { akustiğine ilgi duyan } \\
\text { çeşitli sistemler için } \\
\text { araştırılmaktadır. }\end{array}$ & $\begin{array}{l}\text { FDTD (Finite Difference } \\
\text { Time Domain Method) yön- } \\
\text { temlerinin ses sentezinde, } \\
\text { özellikle büyük, gerçek } \\
\text { dünyadaki fiziksel model- } \\
\text { lere ve nihayetinde 3D'ye } \\
\text { uygulanması. }\end{array}$ \\
\hline
\end{tabular}




\begin{tabular}{|c|c|c|c|c|c|c|}
\hline Makalenin Adı & $\begin{array}{l}\text { Yayınlandığı } \\
\text { Yıl / Yazarlar }\end{array}$ & $\begin{array}{l}\text { Yayınlandığı yer / } \\
\text { Makale türü }\end{array}$ & $\begin{array}{l}\text { Modellenen Fi- } \\
\text { ziksel Cisim ve } \\
\text { Olay }\end{array}$ & $\begin{array}{c}\text { Kullanılan } \\
\text { Yöntem veya } \\
\text { (fiziksel mo- } \\
\text { del) }\end{array}$ & Amacı & Sonucu \\
\hline $\begin{array}{l}\text { 23)Example-Gui- } \\
\text { ded Physically Ba- } \\
\text { sed Modal Sound } \\
\text { Synthesis } \\
\text { (Örnek Kılavuzlu } \\
\text { Fiziksel Tabanlı } \\
\text { Modal Ses Sentezi) }\end{array}$ & $\begin{array}{c}\text { 2013/ } \\
\text { Ren, Z., Yeh, H., } \\
\text { \& Lin, M. C. }\end{array}$ & $\begin{array}{l}\text { ACM Transac- } \\
\text { tions on Grap- } \\
\text { hics (TOG), 32(1), } \\
1-16 \text {. }\end{array}$ & $\begin{array}{c}\text { 3D } \\
\text { Gerçek dünya ka- } \\
\text { yitlarından örnek } \\
\text { bir ses klibi kulla- } \\
\text { narak yeni bir veri } \\
\text { odaklı, fiziksel ta- } \\
\text { banlı ses sentezi } \\
\text { algoritmasının su- } \\
\text { nulması. }\end{array}$ & $\begin{array}{c}\text { Modal Sentez- } \\
\text { leme }\end{array}$ & $\begin{array}{c}\text { Kaydedilen ses mal- } \\
\text { zemelerinin doğal } \\
\text { kalitesini yakalayan } \\
\text { malzeme parametre- } \\
\text { lerini tahmin etmek } \\
\text { için önceden kay- } \\
\text { dedilmiş ses klip- } \\
\text { lerini kullanan yeni } \\
\text { bir yöntemin su- } \\
\text { nulması }\end{array}$ & $\begin{array}{l}\text { Gerçek dünya kayıt- } \\
\text { larından örnek bir ses } \\
\text { klibi kullanarak yeni bir } \\
\text { veri odaklı, fiziksel ta- } \\
\text { banlı ses sentezi algo- } \\
\text { ritması sunulması. }\end{array}$ \\
\hline $\begin{array}{l}\text { 24)Inverse-Foley } \\
\text { Animation: Synch- } \\
\text { ronizing rigid-body } \\
\text { motions to sound } \\
\text { (Ters Foley Ani- } \\
\text { masyonu: Katı ci- } \\
\text { sim hareketlerini } \\
\text { sese senkronize } \\
\text { etme) }\end{array}$ & $\begin{array}{l}\text { 2014/ } \\
\text { Langlois, T. R., } \\
\text { \& James, D. L. }\end{array}$ & $\begin{array}{l}\text { ACM Transac- } \\
\text { tions on Grap- } \\
\text { hics (TOG), 33(4), } \\
1-11 .\end{array}$ & $\begin{array}{c}\text { 3D } \\
\text { Önceden kayde- } \\
\text { dilmiş seslerle } \\
\text { senkronize edilen } \\
\text { katı cisim hare- } \\
\text { ketlerini veya di- } \\
\text { ğer zamansal giriş } \\
\text { sinyallerini sen- } \\
\text { tezlemek için yeni } \\
\text { bir teknik olan } \\
\text { Ters-Foley Ani- } \\
\text { masyonunu tanı- } \\
\text { tılması }\end{array}$ & $\begin{array}{c}\text { Geometrik } \\
\text { Model }\end{array}$ & $\begin{array}{c}\text { Katı cisim animas- } \\
\text { yonlarını optimize } \\
\text { etmek için bir tek- } \\
\text { nik olan Ters-Foley } \\
\text { Animasyonu sunu- } \\
\text { larak temas olayla- } \\
\text { rının giriş ses olay- } \\
\text { larıyla senkronize } \\
\text { edilmesi. }\end{array}$ & $\begin{array}{l}\text { Ters-Foley Animas- } \\
\text { yonu, düzinelerce nesne } \\
\text { ve yüzlerce temas sesi } \\
\text { dizisi için senkronize } \\
\text { hareketleri sentezlemek } \\
\text { için başarılyla kullanıl- } \\
\text { mıştır. }\end{array}$ \\
\hline $\begin{array}{l}\text { 25)SynCoPation: } \\
\text { Interactive Synthe- } \\
\text { sis-Coupled Sound } \\
\text { Propagation } \\
\text { (SynCoPation: Et- } \\
\text { kileşimli Sen- } \\
\text { tez-Çiftli Ses Ya- } \\
\text { y1lımı) }\end{array}$ & $\begin{array}{l}\text { 2016/ } \\
\text { Rungta, A., Sc- } \\
\text { hissler, C., } \\
\text { Mehra, R., Mal- } \\
\text { loy, C., Lin, M., } \\
\text { \& Manocha, D. }\end{array}$ & $\begin{array}{l}\text { IEEE transacti- } \\
\text { ons on visualiza- } \\
\text { tion and computer } \\
\text { graphics, 22(4), } \\
1346-1355 .\end{array}$ & $\begin{array}{c}\text { 3D } \\
\text { Sanal ortamlarda } \\
\text { otomatik olarak } \\
\text { gerçekçi işitsel } \\
\text { içerik oluşturmak } \\
\text { için ses sentezini } \\
\text { ses yay1lımı ile } \\
\text { birleştirmek için } \\
\text { yeni bir tekniğin } \\
\text { sunulması. }\end{array}$ & $\begin{array}{c}\text { Modal Sentez- } \\
\text { leme }\end{array}$ & $\begin{array}{c}\text { Modal ses sentezi, } \\
\text { ses radyasyonu ve } \\
\text { ses yayılımını bir- } \\
\text { leştirerek bilgisa- } \\
\text { yar oyunları ve sanal } \\
\text { gerçeklik için ger- } \\
\text { çekçi ses efektleri } \\
\text { üretebilen ilk birleş- } \\
\text { tirilmiş ses sente- } \\
\text { zi-yayılma algorit- } \\
\text { masının sunulması }\end{array}$ & $\begin{array}{l}\text { Algısal Hankel yakla- } \\
\text { şımı kullanarak dürtü } \\
\text { yanıtlarını hesaplamak } \\
\text { için hızlı bir sşın iz- } \\
\text { leme tekniği ile bu kay- } \\
\text { nak temelini kullanarak } \\
\text { ses yayıllımı gerçekleş- } \\
\text { tirilmiştir. }\end{array}$ \\
\hline $\begin{array}{l}\text { 26)Animating } \\
\text { Elastic Rods with } \\
\text { Sound } \\
\text { (Elastik Çubukların } \\
\text { Sesle Hareketlendi- } \\
\text { rilmesi) }\end{array}$ & $\begin{array}{l}\text { 2017/ Schweic- } \\
\text { kart, E., James, } \\
\text { D. L., \& Mars- } \\
\text { chner, S. }\end{array}$ & $\begin{array}{l}\text { ACM Transac- } \\
\text { tions on Grap- } \\
\text { hics (TOG), 36(4), } \\
1-10 \text {. }\end{array}$ & $\begin{array}{c}\text { 3D } \\
\text { Merdivenlerden } \\
\text { aşağı kayan bir } \\
\text { yayın görsel-işit- } \\
\text { sel simülasyonu }\end{array}$ & $\begin{array}{l}\text { Modal Sentez- } \\
\text { leme }\end{array}$ & $\begin{array}{c}\text { Deforme olabilen } \\
\text { elastik çubuklar için } \\
\text { eşzamanlı animas- } \\
\text { yon ve ses üretimi } \\
\text { için fiziksel tabanlı } \\
\text { yöntemlerin sunul- } \\
\text { ması. }\end{array}$ & $\begin{array}{l}\text { İnce yapılar için aynı } \\
\text { anda ses ve fiziksel ta- } \\
\text { banlı animasyon üretil- } \\
\text { miştir. Model mevcut } \\
\text { 3D simülasyon ortamla- } \\
\text { rına kolayca sığar ve ol- } \\
\text { dukça deforme olabilen } \\
\text { cisimler için bile olası } \\
\text { ses üretebilir. }\end{array}$ \\
\hline
\end{tabular}




\begin{tabular}{|c|c|c|c|c|c|c|}
\hline Makalenin Adı & $\begin{array}{c}\text { Yayınlandığı } \\
\text { Yıl / Yazarlar }\end{array}$ & $\begin{array}{l}\text { Yayınlandığı yer / } \\
\text { Makale türü }\end{array}$ & $\begin{array}{l}\text { Modellenen } \\
\text { Fiziksel Ci- } \\
\text { sim ve Olay }\end{array}$ & \begin{tabular}{|c|} 
Kullanılan \\
Yöntem veya \\
(fiziksel mo- \\
del)
\end{tabular} & Amacı & Sonucu \\
\hline $\begin{array}{l}\text { 27) Model-based } \\
\text { digital pianos: from } \\
\text { physics to sound } \\
\text { synthesis } \\
\text { (Model tabanlı diji- } \\
\text { tal piyanolar: fizik- } \\
\text { ten ses sentezine) }\end{array}$ & $\begin{array}{c}\text { 2018/ } \\
\text { Bank, B., \& } \\
\text { Chabassier, J. }\end{array}$ & $\begin{array}{l}\text { IEEE Signal Pro- } \\
\text { cessing Magazine, } \\
36(1), 103-114 .\end{array}$ & $\begin{array}{c}\text { 3D } \\
\text { Enstrümanın } \\
\text { fiziksel tanı- } \\
\text { mına dayana- } \\
\text { rak mevcut } \\
\text { piyano mo- } \\
\text { dellerinin ana } \\
\text { özelliklerini } \\
\text { gözden geçi- } \\
\text { rilmesi }\end{array}$ & $\begin{array}{l}\text { Modal Sentez- } \\
\text { leme }\end{array}$ & $\begin{array}{l}\text { Hesaplamalı olarak } \\
\text { ağır, fiziksel olarak } \\
\text { doğru yaklaşımlar- } \\
\text { dan başlayarak fi- } \\
\text { zik tabanlı piyano } \\
\text { sentezine genel bir } \\
\text { bakış sunmak ve } \\
\text { daha sonra gerçek } \\
\text { zamanlı sentezde } \\
\text { mümkün olan en iyi } \\
\text { ses kalitesini hedef- } \\
\text { lemek }\end{array}$ & $\begin{array}{l}\text { Enstrümanın fiziksel ta- } \\
\text { nımına dayanarak mev- } \\
\text { cut piyano modellerinin ana } \\
\text { özelliklerini gözden geçiril- } \\
\text { miştir. Bu modeller, enstrü- } \\
\text { manın işleyişini anlamaya } \\
\text { izin verirken, üretilen ses- } \\
\text { ler hayal kırıklığı yaratıyor } \\
\text { çünkü birçok özellik eksik, } \\
\text { aynı zamanda bazı olgular } \\
\text { henüz doğru bir şekilde mo- } \\
\text { dellenmemiştir. }\end{array}$ \\
\hline $\begin{array}{l}\text { 28) Model-Ba- } \\
\text { sed Digital Pianos } \\
\text { From physics to } \\
\text { sound synthesis } \\
\text { (Model tabanll diji- } \\
\text { tal piyanolar Fizik- } \\
\text { ten ses sentezine) }\end{array}$ & $\begin{array}{c}\text { 2019/ } \\
\text { B. Bank and J. } \\
\text { Chabassier }\end{array}$ & $\begin{array}{l}\text { Model-Based Di- } \\
\text { gital Pianos: From } \\
\text { Physics to Sound } \\
\text { Synthesis," in } \\
\text { IEEE Signal Pro- } \\
\text { cessing Magazine, } \\
\text { vol. 36, no. 1, pp. } \\
\text { 103-114. }\end{array}$ & $\begin{array}{l}\text { 3D } \\
\text { Enstrümanın } \\
\text { fiziksel tan1- } \\
\text { mına dayana- } \\
\text { rak mevcut } \\
\text { piyano mo- } \\
\text { dellerinin ana } \\
\text { özelliklerini } \\
\text { gözden geçi- } \\
\text { rilmesi }\end{array}$ & $\begin{array}{l}\text { Modal Sentez- } \\
\text { leme }\end{array}$ & $\begin{array}{l}\text { Gerçek zamanlı sen- } \\
\text { tez için mümkün } \\
\text { olan en iyi ses kali- } \\
\text { tesini üretmek üzere } \\
\text { tasarlanan yaklaşım- } \\
\text { ların tartışıldığı, he- } \\
\text { sapsal olarak ağır, fi- } \\
\text { ziksel olarak doğru } \\
\text { bir yaklaşımla başla- } \\
\text { yan fizik tabanlı bir } \\
\text { piyano sentezine ge- } \\
\text { nel bir bakışın su- } \\
\text { nulması. }\end{array}$ & $\begin{array}{l}\text { Hesaplamalı gücün artma- } \\
\text { siyla birlikte, bu mevcut } \\
\text { modellerin gelişmeye de- } \\
\text { vam etmesi ve piyano sen- } \\
\text { tezi için fiziksel modelleme } \\
\text { kullanan diğer ticari ürün- } \\
\text { ler (benzer fiziksel işlev- } \\
\text { lere sahip diğer telli çalgl- } \\
\text { lar) için kullanılabilir hale } \\
\text { getirmek. }\end{array}$ \\
\hline $\begin{array}{l}\text { 29) Physical Mo- } \\
\text { deling, Algorithms, } \\
\text { and Sound Synt- } \\
\text { hesis: The NESS } \\
\text { Project } \\
\text { (Fiziksel Model- } \\
\text { leme, Algoritma- } \\
\text { lar ve Ses Sentezi: } \\
\text { NESS Projesi) }\end{array}$ & $\begin{array}{l}\text { 2020/ } \\
\text { Bilbao, S., Des- } \\
\text { vages, C., Duc- } \\
\text { ceschi, M., Ha- } \\
\text { milton, B., } \\
\text { Harrison-Hars- } \\
\text { ley, R., Torin, } \\
\text { A., \& Webb, C. }\end{array}$ & $\begin{array}{l}\text { Physical Mode- } \\
\text { ling, Algorithms, } \\
\text { and Sound Synt- } \\
\text { hesis: The NESS } \\
\text { Project. Compu- } \\
\text { ter Music Journal, } \\
43(2-3), 15-30 .\end{array}$ & $\begin{array}{c}3 \mathrm{D} \\
\text { Yeni nesil ses } \\
\text { sentezinin so- } \\
\text { nuçları sunul- } \\
\text { ması. }\end{array}$ & $\begin{array}{l}\text { Modal Sentez- } \\
\text { leme }\end{array}$ & $\begin{array}{l}\text { Yeni nesil ses sen- } \\
\text { tezi, yaylı-telli çal- } \\
\text { gılar, fiziksel mo- } \\
\text { delleme için büyük } \\
\text { ölçekli ortamlar da } \\
\text { dahil olmak üzere } \\
\text { çeşitli ses üretim sis- } \\
\text { temleri için algorit- } \\
\text { manın sunulması. }\end{array}$ & $\begin{array}{l}\text { Zaman alanındaki sayısal } \\
\text { simülasyon için genel tek- } \\
\text { nikler, fiziksel modelleme } \\
\text { sentezi için karmaşık mü- } \\
\text { zik aletlerinin simülasyo- } \\
\text { nuna genel bir yaklaşımın } \\
\text { sunulması. }\end{array}$ \\
\hline
\end{tabular}




\section{Tablo 1'de özetlenen araştırmalarda kullanılan Fizik Tabanlı Ses Sentezi Modelleri}

Fizik tabanlı ses sentezinde kullanılan başlıca matematiksel modeller genellikle sonlu elemanlar metodu veya sonlu farklar metodu ile birlikte kullanılan modal sentezleme yöntemi, kütle-yay modeli, geometrik model, stokastik modeller, dalga kılavuzu modelleri olarak siralanabilir. Bu çalışmada taranan yayınlarda en sık kullanılan metotların teorisi özetlenmiştir. Şekil 2.1.'de görüldüğü gibi tüm modeller öncelikle gerçek sistemin ya da cismin ses elde ediliği durumunu en doğru şekilde açıklayan fiziksel modelin ve parametrelerinin belirlenmesi ile başlar. Daha sonra bu fiziksel modeli bilgisayar üzerinde çalıştıracak uygun algoritmaların geliştirilmesi ve teorik sonuçlara göre simülasyonun optimize edilmesi ve güncellenmesi gerekmektedir.

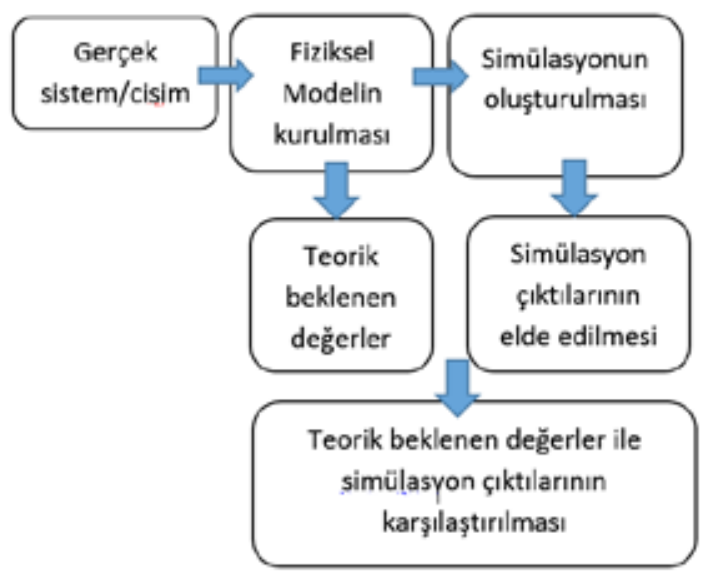

Şekil 2.1. Gerçek bir sistem ya da cismin fiziğe dayalı ses simülasyonu oluşturulurken genel olarak izlenen adımlar. 


\subsection{Modal Sentezleme Yöntemi}

Fiziksel modelleme ile ses sentezinde kullanılan uzun geçmişine sahip farklı bir yaklaşım, bir frekans alanına (domain) veya kütlesi farklı alanlara dağılmış nesnelerin titreşiminin modal (kip) tanımına dayanır. Modal sentez, titreşimli bir nesnenin karmaşık dinamik davranışını bir dizi mod (uzamsal biçimleri eldeki problemin öz-fonksiyonlarına ve sınır şartlarına bağlı parçalar) grubunun katkıları ile inceler. $\mathrm{Bu}$ tür modların her biri, tek bir karmaşık frekansta salınır. Gerçek değerli problemler için, bu karmaşık frekanslar karmaşık eşlenik çiftlerde ortaya çıkar ve "mod" bu öz-fonksiyonların ve frekansların çifti olarak kabul edilebilir. Sinüzoitlerin insan sesi algısındaki özel önemini göz önünde bulundurarak, böyle bir ayrışma, özellikle ses sentezi anlamında yararlı fikirlere yol açabilir.

Modal sentez, ilaveli sentez olarak, bir kaynağın eklenen birçok bileşen ile tanımlanmasını içerir. Modal sentezleme modelinde, mod frekanslarının vektöründen, bozulma oranları vektöründen ve nesne yüzeyinin farklı konumlarında her bir mod için tanımlanmış kazanç matrisinden oluşur. Osilatörlerin frekansları ve sönümleri, nesnenin geometrisi ve malzeme özellikleri tarafından yönetilirken, modların bağlantı kazançları, mod şekilleri tarafından belirlenir ve nesnenin temas yerine bağlıdır. Analiz edilen nesne isteğe bağlı bir şekle sahip olabileceğinden, modal analiz yapmak için genellikle sonlu elemanlar yöntemi (FEM) kullanılır, bu da genel olarak tatmin edici sonuçlar verir (Limpens,2009). 


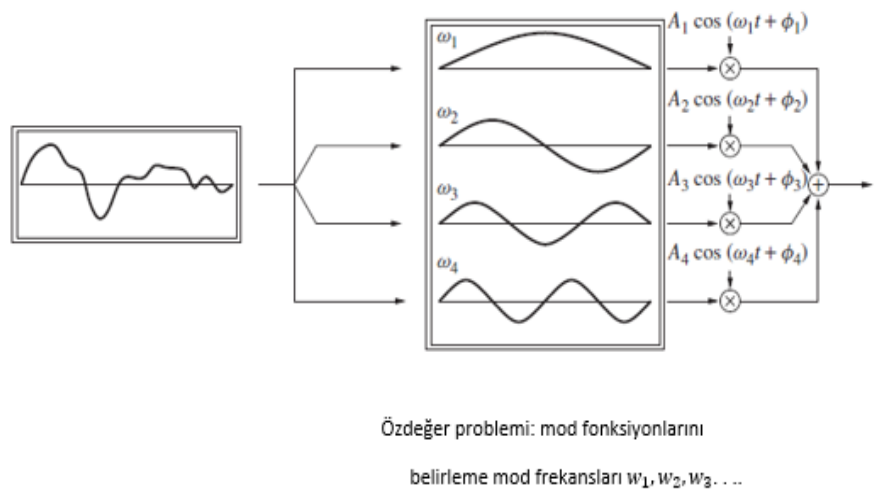

Şekil 2.2. Modal sentez: Doğrusal, dağınık zamana bağlı bir sorunun davranışı, her biri belirli titreşim frekansına sahip çeşitli modlara ayrılabilir. Ses çıkışı, uyarma ve çıkış parametrelerine bağlı olarak bu tür frekansların yeniden birleştirilmesiyle elde edilebilir.

$\mathrm{Bu}$ tür modların her biri, tek bir frekansta salınır. Modal sentez, MOSAIC ve Modalys ses sentezi yazılım paketlerinin temelini oluşturur ve CORDIS ile birlikte fiziksel modelleme ilkelerini kullanan ilk kapsamlı sistemlerden biriydi. Daha yakın zamanlarda, başta Rabenstein ve Trautmann olmak üzere çeşitli araştırmacılar, noktadan noktaya transfer fonksiyonlarını türetmek için modal teknikleri kullanan fonksiyonel dönüşüm yöntemi (FTM) adı verilen ilgili bir yöntem geliştirdiler. Temel modal sentez stratejisi Şekil 2.2'de gösterildiği gibidir. Dört farklı frekanstaki temel sinüs işareti birleşerek solda görülen işareti oluşturmaktadır.

Modal sentez genellikle "frekans alan" yöntemi olarak adlandırılsa da bu işleminin doğru bir tanımı değildir. Geçici Fourier dönüşümleri kullanılmaz ve çıkış dalga formu doğrudan zaman alanında üretilir. Esasen, her bir mod skaler ikinci dereceden siradan diferansiyel denklem ile tanımlanır ve sayısal bir çözüm elde etmek için çeşitli zaman entegrasyon teknikleri kullanılabilir. Kısacası, modal sentezi bir frekans etki alanı yöntemi olarak değil, köşegenleştirilen doğrusal bir problem için sayısal bir yöntem olarak düşünmek daha iyidir (Bilbao,2009). 


\subsection{Kütle-Yay Sistemi}

Sonlu elemanlara benzer şekilde, kütle etkileşimi, hücresel veya parçacık sistemleri olarak da adlandırılan kütle-yay sistem, bir nesneyi küçük parçacıklara ayırarak onların kütle-yay çiftlerinden kurulmasını amaçlar. Kütle yay sistemleri tartışmasız tüm deforme olabilen modellerin en basit ve en sezgisel sistemidir. Sadece kütlesiz bir yay ağı ile birbirine bağlanan nokta kütlelerinden oluşur ve her parçacığın hareketi daha sonra Newton'un ikinci yasası tarafından yönetilir. Bu nedenle, kütle-yay sistemleri sadece birleşik adi diferansiyel denklemler (ODE’ler) sisteminin çözümünü gerektirir.

Ayrık fiziksel modeller kullanılarak nesnelerin yüzey titreşimlerinin gerçek zamanda modellenmesi, Florens ve Cadoz [Florens 1991] tarafından 3D şekilleri modellemek için kullanılan sönümlü bir kütle yay sistemi ile tanıtılmıştır. CORDIS-ANIMA sistemi daha sonra fiziksel tabanlı ses sentezi için geliştirilmiştir. Bir kütle-yay modeli, bir nesnenin geometrisine ve birkaç malzeme parametresine dayanarak yüzey deformasyonuna yaklaşmak üzere inşa edilmiştir. Önceki yaklaşımlarda kullanılan FEM (Finite Element Model) modellerinden daha kaba yaklaşım yapmalarına rağmen, kütle-yay sistemlerinin ses üreten yüzeylerin mikro titreşimlerini uygun bir şekilde modellediği görülmektedir (Limpens,2009).

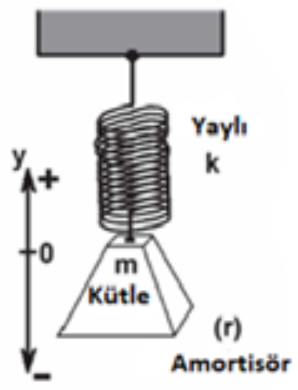

Şekil 2.3 Kütle-yay sistemi 
Şekil 2.3'de yaya bağlı bir kütleden oluşan mekanik bir sistem gösterilmektedir. Kütle m ile gösterilmiştir. İdeal bir yay, onu dinlenme konumundan çıkarmak için gerekli kuvvet ile karakterize edilir: Birim mesafe başına bu kuvvet k ile gösterilir. Kütlenin yer değiştirmesi, yukarı doğru yer değiştirme için pozitif ve aşağ1 doğru yer değiştirme için negatif değer alan bir y değişkeni ile gösterilir.

Yayın sıkışması ve gerilmesi 1sı kaybına ve kütle-yay üzerinde hava direnci gibi kayıplara yol açar. Toplam kayıplar $r$ ile gösterilir.

$$
\begin{aligned}
& F=m a \\
& -k y-m g-r v=m a
\end{aligned}
$$

- $k y$ terimi $F$ kuvveti altında hareket eden yay kuvvetini temsil eder. Kütle aşağı çekilirse, $-k y$ kuvveti pozitiftir, çünkü $y$ negatiftir. - $m g$ terimi kütleye etkiyen yerçekimidir. $-r v$ terimi ise, $v$ hızıyla orantılı olarak hareket eden sistemin kayıp kuvvetlerini yansıtır. Hız ve ivme için matematiksel ifadeler denklem 2.2'de verilmiştir (Cook, 2002).

$$
v=d y / d t \quad a=\frac{d v}{d t}=d^{2} y / d t^{2}
$$

Özellikle 1-D cisimlerin (gitar teli, insan saçı vb) görsel modellemesinde kullanılan kütle-yay sistemi, 1-D cisimlerin çıkaracağı seslerin de sentezini modellemede tercih edilmektedir.

\subsection{Sonlu Elemanlar Yöntemi}

Sonlu elemanlar yöntemi, günümüzde karmaşık mühendislik problemlerinin hassas olarak çözülmesinde etkin olarak kullanılan bir sayısal yöntemdir. $\mathrm{Bu}$ yöntem, "parçadan bütüne gitme" genel prensibine dayanmaktadır.

Sonlu elemanlar yöntemi, karmaşık bir problemi basite indirgeyerek çözüme götürmeyi amaçlar. Bu yöntemde çözüm bölgesi sonlu eleman adı verilen çok sayıda, basit, küçük ve birbirine bağlı alt bölgelere 
ayrılmaktadır. Kısacası burada oldukça büyük olan bir model daha kolay çözülebilsin diye çok sayıda düğüm noktalarıyla birbirlerine bağlanmış küçük parçalara ayrılmaktadır (Şekil 2.4.).

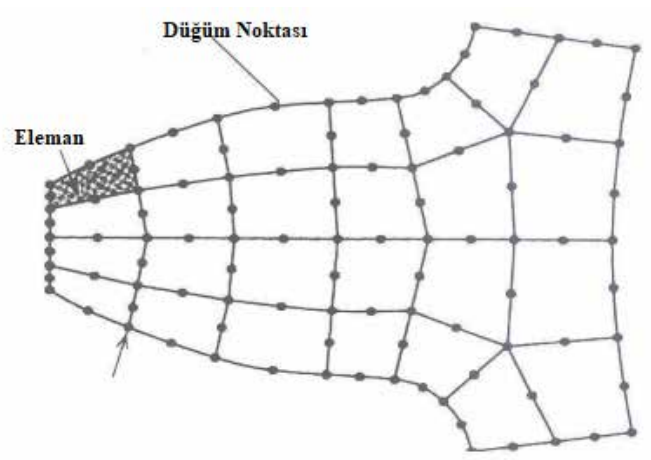

Şekil 2.4. Sonlu elemanlarla tanımlanmış bir yüzey üzerinde Düğüm Noktası ve Yüzey-Elemanı

Şekil 2.4. bir yüzeyin modellenmesi için kullanılmakla birlikte, yüzey titreşimi ile oluşan sesin de modellenmesinde kullanılabilir. Özellikle birbirleri ile çarpışan cisimlerin yüzeysel titreşimler sebebi ile çıkaracağı seslerin modellenmesi için uygun bir yöntemdir.

\subsection{Geometrik Yöntem}

Geometrik model bazen üç boyutlu (3D) bilgisayar destekli tasarım (CAD) modeli olarak adlandırılır ve fiziksel sistemleri tasarlamak için gerekli olan kritik bir gösterimdir. Geometrik model, SysML (Sistem Modelleme Dili) modelinin bir parçası değildir, ancak iki model, sistemin her iki temsilinin de birbiriyle tutarlı olmasını sağlamak için entegre edilebilir. Geometrik model, sistemin ve bileşenlerinin başka bir görünümüdür. Belirli bir bileşenin mekânsal boyutunu belirleyen geometrik ilişkileri açıklar. CAD modeli, malzeme özellikleri gibi birçok ek özellik de içerebilir. 
SysML 'deki sistem modeli ve CAD modeli, bir sistemin kavramsal tasarım aşamasından başlayıp geliştirme yaşam döngüsü boyunca devam ederek eş zamanlı olarak geliştirilmelidir. Sistem modeli işlevselliği, arabirimi, performansı ve kalite özelliklerini belirleyen bileşenin soyut bir temsilini sağlarken, CAD modeli bileşenin geometrik temsilini sağlar. Sistem modeli, gereksinimlerle bileşen ilişkileri kurabilir, daha genel bileşenleri tanımlayabilir ve bileşenlerin ortamını belirtebilir. Sistem modeli, geometrik modelin gerçekleştirebileceği özellik bilgileri sağlar. Geometrik model ise, kritik boyutlandırma ve toleranslar, diğer fiziksel özellikler ve mekanik ara bağlantı da dahil olmak üzere sistem modeline temel bilgiler sağlar (Friedenthal,2015).

\section{Sonuçlar}

Bu çalışmada 1993-2020 yılları arasında yayınlanmış, fizik tabanlı ses sentezi simülasyon örneklerini içeren çalışmalar incelenmiş ve özetlenmiştir.

Son yıllarda, fiziksel etkileşimlerin görsel gerçekçiliğini mümkün kılan hesaplama tekniklerinin gelişmesi, algısal yaklaşımların ve hesaplama gücünün arttırılması ile bilgisayar grafikleri alanında interaktif uygulamalarda gelişim görülmeye devam etmektedir. Benzer şekilde interaktif ses sentezi çalışmaları da güncel araştırma konuları arasindadir.

Bilgisayarların teknik özellikleri de geliştikçe daha karmaşık olayları fiziksel modeller ile simüle edebilmek, daha az hesaplama maliyetli çözümler üretmek mümkün olmaya başlamıştır.

Özellikle interaktif cisimlerin ürettiği seslerin, cisimlerin görüntüleri ile birlikte fizik tabanlı modellenmesi için farklı yaklaşımların bir arada kullanılması gerekmektedir.

Fizik tabanlı modellerin ortak özelliği; gerçek hayatta sesin oluşumuna sebep olacak etkileşimlerin, insan kulağının algılayabildiği frekansta ses işaretlerini üretecek fiziksel kurallara uygun bu modelin, yazılım ile birlikte bir bilgisayar donanımına tatbik edilebilmeye uygun olmasidir. 
Cisimlerin geometrik şekillerine, birbirleri ile interaktif etkileşimlerinin türüne, maddesel yapılarına (kat1, sıvı), görsel simülasyonla birlikte sesin üretilmesine, kisaca simüle edilmek istenen fiziksel olaya göre kullanımı uygun olan bir çok fizik tabanlı model geliştirilmiştir. Yöntemlerin bir arada kullanıldığı karma modeller hesaplama güçlüklerinin giderilmesi ve yazılım desteği ile uyumun sağlanmasına katkı sağlamaktadır.

Not: Bu yayın İstanbul Ticaret Üniversitesi, Fen Bilimleri Enstitüsü Bilgisayar Mühendisliği Bölümü Yüksek Lisans öğrencisi Elif Ekşi'nin tezinden üretilmiştir.

\section{Kaynaklar}

[1] Karjalainen, M., Välimäki, V., \& Jánosy, Z. (1993, September). Towards high-quality sound synthesis of the guitar and string instruments. In Proceedings of the International Computer Music Conference (pp. 56-56).

[2] De Poli, G., \& Rocchesso, D. (1998). Physically based sound modelling. Organised Sound, 3(1), 61-76.

[3] Van Den Doel, K., Kry, P. G., \& Pai, D. K., (2001)," FOLEYAUTOMATIC: Physically-based Sound Effects for Interactive Simulation and Animation In Proceedings of the 28th annual conference on Computer graphics and interactive techniques (pp. 537-544).

[4] Pai, D. K., Doel, K. V. D., James, D. L., Lang, J., Lloyd, J. E., Richmond, J. L., \& Yau, S. H., (2001)," Scanning Physical Interaction Behavior of 3D Objects", In Proceedings of the 28th annual conference on Computer graphics and interactive techniques (pp. 87-96).

[5] O'Brien, J. F., Cook, P. R., \& Essl, G., (2001)," Synthesizing Sounds from Physically Based Motion", Synthesizing sounds from physically based motion. In Proceedings of the 28th annual conference on Computer graphics and interactive techniques (pp. 529-536).

[6] Rath, M., Rocchesso, D., \& Avanzini, F., (2002)," Physically-based real-time modeling of contact sounds", In Proc. Int. Computer Music Conf.).

[7] Cook, P. R., (2002)," Sound Production and Modeling", Sound production and modeling. IEEE Computer Graphics and applications, 22(4), 23-27. 
[8] Bank, B., Avanzini, F., Borin, G., De Poli, G., Fontana, F., \& Rocchesso, D., (2003)," Physically Informed Signal Processing Methods for Piano Sound Synthesis: A Research Overview", Physically informed signal processing methods for piano sound synthesis: a research overview. EURASIP Journal on Advances in Signal Processing, 2003(10), 464536.

[9] Doel, K. V. D. (2005). Physically based models for liquid sounds. ACM Transactions on Applied Perception (TAP), 2(4), 534-546.

[10] Zhang, Q., Ye, L., \& Pan, Z., (2005)," Physically-based Sound Synthesis on GPUs", In International Conference on Entertainment Computing (pp. 328333). Springer, Berlin, Heidelberg.

[11] Raghuvanshi, N., \& Lin, M. C., (2006)," Interactive Sound Synthesis for Large Scale Environments", In Proceedings of the 2006 symposium on Interactive 3D graphics and games (pp. 101-108).

[12] Barbic, D. L. J. J., \& Pai, D. K., (2006), "Precomputed Acoustic Transfer: Output-sensitive, accurate sound generation for geometrically complex vibration sources", Precomputed Acoustic Transfer: Output-sensitive, accurate sound generation for geometrically complex vibration sources.

[13] Raghuvanshi, N., \& Lin, M. C., (2007),” Physically Based Sound Synthesis for Large-Scale Virtual Environments", IEEE Computer Graphics and Applications, 27(1), 14-18.

[14] Rabenstein, R., Petrausch, S., Sarti, A., De Sanctis, G., Erkut, C., \& Karjalainen, M. (2007). Blocked-based physical modeling for digital sound synthesis. IEEE Signal Processing Magazine, 24(2), 42-54.

[15] Peltola, L., Erkut, C., Cook, P. R., \& Valimaki, V., (2007), "Synthesis of Hand Clapping Sounds", IEEE Transactions on Audio, Speech, and Language Processing, 15(3), 1021-1029.

[16] Bergou, M., Wardetzky, M., Robinson, S., Audoly, B., \& Grinspun, E., (2008),” Discrete Elastic Rods", In ACM SIGGRAPH 2008 papers (pp. 1-12).

[17] Chadwick, J. N., An, S. S., \& James, D. L., (2009), "Harmonic Shells: A Practical Nonlinear Sound Model for Near-Rigid Thin Shells", ACM Trans. Graph., 28(5), 119.

[18] Zheng, C., \& James, D. L., (2009)," Harmonic Fluids", ACM Transactions on Graphics (TOG), 28(3), 1-12.

[19] Chadwick, J. N., \& James, D. L., (2011)," Animating Fire with Sound”, ACM Transactions on Graphics (TOG), 30(4), 1-8.

[20] Chadwick, J. N., Zheng, C., \& James, D. L., (2012), "Precomputed Acceleration Noise for Improved Rigid-Body Sound", ACM Transactions on Graphics (TOG), 31(4), 1-9. 
[21] An, S. S., James, D. L., \& Marschner, S., (2012), "Motion-driven Concatenative Synthesis of Cloth Sounds" ACM Transactions on Graphics (TOG), 31(4), $1-10$.

[22] Bilbao, S., Hamilton, B., Torin, A., Webb, C., Graham, P., Gray, A., ... \& Perry, J., (2013), "Large Scale Physical Modeling Sound Synthesis", In Proceedings of the Stockholm music acoustic conference (SMAC2013), Stockholm (pp. 593-600).

[23] Ren, Z., Yeh, H., \& Lin, M. C., (2013), "Example-Guided Physically Based Modal Sound Synthesis", ACM Transactions on Graphics (TOG), 32(1), 1-16.

[24] Langlois, T. R., \& James, D. L., (2014), "Inverse-Foley Animation: Synchronizing rigid-body motions to sound", ACM Transactions on Graphics (TOG), 33(4), 1-11.

[25] Rungta, A., Schissler, C., Mehra, R., Malloy, C., Lin, M., \& Manocha, D., (2016), "SynCoPation: Interactive Synthesis-Coupled Sound Propagation", IEEE transactions on visualization and computer graphics, 22(4), 1346-1355.

[26] Schweickart, E., James, D. L., \& Marschner, S., (2017), “Animating Elastic Rods with Sound", ACM Transactions on Graphics (TOG), 36(4), 1-10.

[27] Bank, B., \& Chabassier, J., (2018), "Model-based digital pianos: from physics to sound synthesis", IEEE Signal Processing Magazine, 36(1), 103-114.

[28] B. Bank and J. Chabassier, (2019), "Model-Based Digital Pianos From physics to sound synthesis", IEEE Signal Processing Magazine, vol. 36, no. 1, pp. 103114.

[29] Bilbao, S., Desvages, C., Ducceschi, M., Hamilton, B., Harrison-Harsley, R., Torin, A., \& Webb, C., (2020), "Physical Modeling, Algorithms, and Sound Synthesis: The NESS Project", The NESS Project. Computer Music Journal, 43(2-3), 15-30.

[30] Bilbao, S., (2009), Numerical Sound Synthesis, Singapur, John Wiley \& Sons.

[31] Cook P., (2002), Real Sound Synthesis for Interactive Applications, New York, Routledge.

[32] https://(www.serdarkorkut.com). [09,05,2017, sonlu-elemanlar-metodu]

[33] Friedenthal, S., Moore, A., Steiner, R., (2015), A Practical Guide to SysML The Systems Modeling Language, United States of America, Morgan Kaufmann. 